\title{
O USO DA MADEIRA NAS REDUÇÕES \\ JESUÍTICO-GUARANI DO RIO GRANDE DO SUL. \\ 5 - FRAGMENTO DE MADEIRA PROCEDENTE \\ DE ESCAVAÇÕES ARQUEOLÓGICAS \\ NO ÁTRIO DA IGREJA DE SÃO LOURENÇO ${ }^{1}$
}

\section{JOSÉNEWTONCARDOSOMARCHIORI² MARIA CRISTINA SCHULZE-HOFER ${ }^{3}$}

\section{RESUMO}

A amostra de madeira obtida em escavações arqueológicas no átrio da igreja de São Lourenço Mártir foi anatomicamente identificada como ipê-roxo, Tabebuia heptaphylla (Vell.) Toledo, espécie notável por sua resistência físico-mecânica e durabilidade natural.

Palavras-chave: Tabebuia heptaphylla, Anatomia da Madeira, Missões Jesuíticas, Rio Grande do Sul.

\section{SUMMARY}

[Wood utilization in the Jesuitic-Guarani Missions from Rio Grande do Sul state, Brazil.

Wood fragment from archeological excavations in the atrium of Saint Lawrence Martyr's church]. The wood sample collected during archeological research in the atrium of Saint Lawrence Martyr's church is presently identified as Tabebuia heptaphylla (Vell.) Toledo, a southern brazilian species notable for its strength and decay resistance.

Key words: Tabebuia heptaphylla, Wood Anatomy, Jesuitic Missions, Rio Grande do Sul, Brazil.

\section{INTRODUÇÃO}

Integrante do arquivo arqueológico do IPHAN, o fragmento de madeira, objeto do presente estudo anatômico, foi obtido de escavações realizadas no átrio da igreja de São Lourenço Mártir e corresponde a um fragmento da parte carbonizada do esteio, provavelmente da estrutura original. ${ }^{4}$ Ao identificar anatomicamente o material, dá-se seguimento à investigação sobre o uso da madeira nas Reduções Jesuítico-Guarani do Rio Grande do Sul, contribuindo para o conhecimento sobre as técnicas construtivas deste singular período da história regional.

${ }^{1}$ Recebido em 10-8-2008 e aceito para publicação em 3010-2008.

2 Engenheiro Florestal, Dr., Professor Titular do Departamento de Ciências Florestais, Universidade Federal de Santa Maria, RS. Bolsista de Produtividade em Pesquisa, $\mathrm{CNPq}$ - Brasil.balduinia@mail.ufsm.br

3 Arquiteta e Urbanista, Dra., IPHAN - Instituto do Patrimônio Histórico e Artístico Nacional. schulzehofer@gmx.de

${ }^{4}$ Informação pessoal de Luiz Antônio Bolcato Custódio, arquiteto do IPHAN.

\section{MATERIAL E MÉTODOS}

O material examinado (Figura 1C), conservado no arquivo arqueológico do IPHAN, resulta de escavações realizadas na década de 1980, no sítio missioneiro de São Lourenço Mártir (Figura 1A). A amostra retirada para estudo foi registrada em fichário, fotografada, acondicionada em envelope com identificação (Figura 1B) e enviada ao Laboratório de Anatomia da Madeira do Instituto Nacional de Pesquisas da Madeira, em LohbrüggeHamburgo (Alemanha), onde foram realizados os trabalhos de microtécnica e fotomicrografia. Os autores agradecem à Sra. Eda John, pela colaboração nessas tarefas.

$\mathrm{Da}$ amostra de madeira foram preparados corpos-de-prova, orientados para a obtenção de cortes anatômicos nos planos transversal, longitudinal radial e longitudinal tangencial. Os corpos-de-prova foram fervidos em água até a expulsão completa do ar, incluídos em PEG 2000 e seccionados em micrótomo de deslizamento (modelo American Optical), regulado para a 

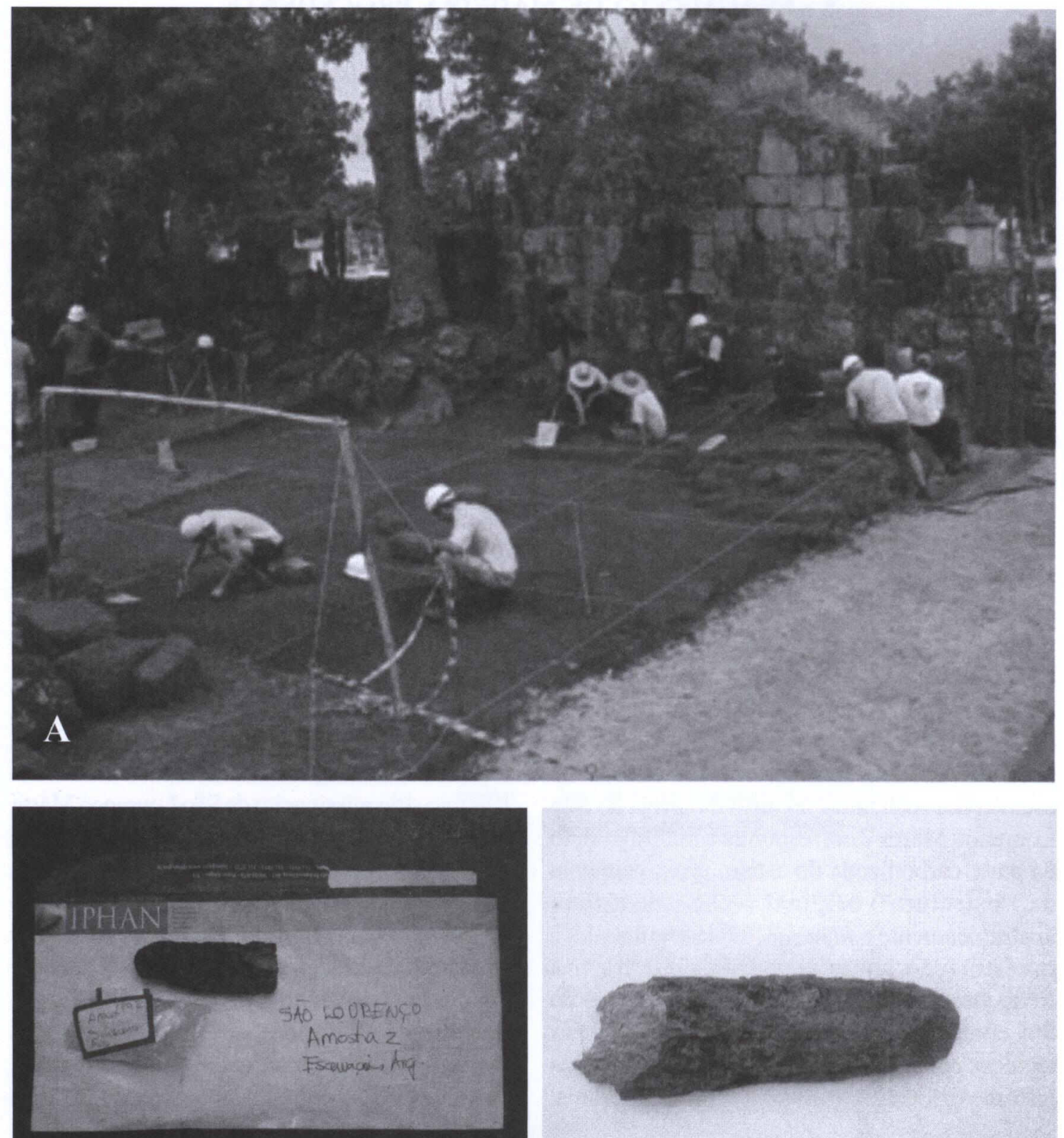

B

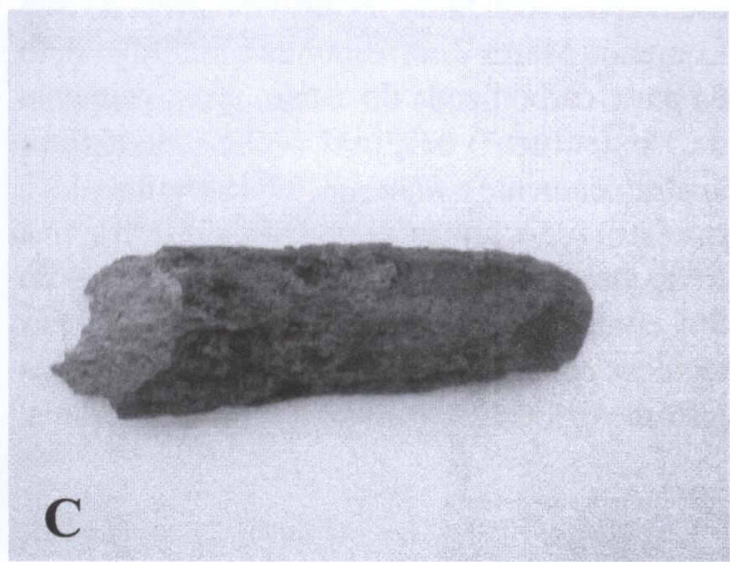

Figura 1 - Escavações arqueológicas em São Lourenço Mártir. A- Registro fotográfico do trabalho. B - Amostra de madeira e respectivo envelope, com identificação. C - Detalhe da amostra investigada. 
obtenção de cortes anatômicos com espessura nominal de $20 \mu \mathrm{m}$. No caso dos cortes radiais, parte deles foi tratado com hipoclorito de sódio, com vistas a salientar a presença de cristais de sílica e oxalato de cálcio. As fotomicrografias da Figura 2 foram tomadas com câmara Olympus AX, com diferentes aumentos.

\section{DESCRIÇÃO ANATÔMICA}

Anéis de crescimento distintos, em plano transversal (Figura 2A). Porosidade difusa (Figura 2A, B). Poros muito numerosos, de 80$110 \mu \mathrm{m}$ de diâmetro, ovais ou arredondados (Figura 2A, B), geralmente solitários e em múltiplos radiais de 2-3 (Figura 2A, B), raro 4 unidades. Madeira de estratificação completa, incluindo elementos vasculares, parênquima axial, raios e fibras (Figura 2E, F).

Elementos vasculares retilíneos (Figura 2C, E, F), com placas de perfuração simples e abundante conteúdo amarelado na cavidade celular (Figura 2F). Pontoações intervasculares alternas, não ornamentadas, de 12 a $14 \mu \mathrm{m}$ de diâmetro, com aréola circular e abertura lenticular inclusa. Espessamentos espiralados ausentes.

Parênquima vasicêntrico incompleto, sem formar, todavia, faixas concêntricas (Figura 2A, B). Séries parenquimáticas, geralmente de duas células.

Raios homogêneos, com freqüência de 5-10/ $\mathrm{mm}$ (Figura 2E), compostos inteiramente de células procumbentes. (Figura 2D). Raios com menos de 10 células de altura e geralmente trisseriados, menos comumente uni e multisseriados (Figura 2E, F).

Fibras libriformes de paredes espessas a muito espessas (Figura 2B).

\section{ANÁLISE ANATÔMICA E DISCUSSÃO}

As pontoações intervasculares não ornamentadas, juntamente com porosidade difusa, ausência de espessamentos espiralados e raios estreitos e baixos, com menos de 10 células de altura, remetem a amostra examinada à família Bignoniaceae, segundo chave dicotômica para madeiras americanas com estrutura estratificada (Record, 1943).

A porosidade difusa, a abundância de conteúdo amarelado nos vasos, o parênquima escassamente vasicêntrico, aliforme até confluente, e os raios finos e baixos, com 3-4 (raro mais) células de largura e menos de 10 células em altura, incluem o material no "grupo Lapacho" do gênero Tabebuia, de acordo com chave dicotômica para as Bignoniáceas americanas (Record \& Hess, 1940). Composto de numerosas espécies e ampla distribuição geográfica, o referido grupo distingue-se das demais seções de Tabebuia pela cor castanhoesverdeada e alta densidade da madeira, bem como pela presença de abundantes depósitos amarelados (lapachol) em vasos do cerne (Record \& Hess, 1943).

O exame comparativo dos três cortes anatômicos com lâminas da coleção do Departamento de Ciências Florestais da Universidade Federal de Santa Maria, permite identificar o material como Tabebuia heptaphylla (Vell.) Toledo - o popular ipê-roxo -, pelos raios relativamente finos e parênquima vasicêntrico incompleto, com tendência a confluente, sem formar, todavia, faixas concêntricas. A utilização dessa espécie de madeira, por sua vez, encontra respaldo em relatos de cronistas do período jesuítico, notadamente de Cardiel e Sepp, além de Félix de Azara, que visitou as Missões no século XVIII.

Em "Las Misiones del Paraguay", Cardiel (1989) informa que para "pilares o horcones" usava-se preferencialmente a madeira de "arboles muy altos y gruesos llamados Tajivos", grafia da época para Tají ou Tají-hü, 

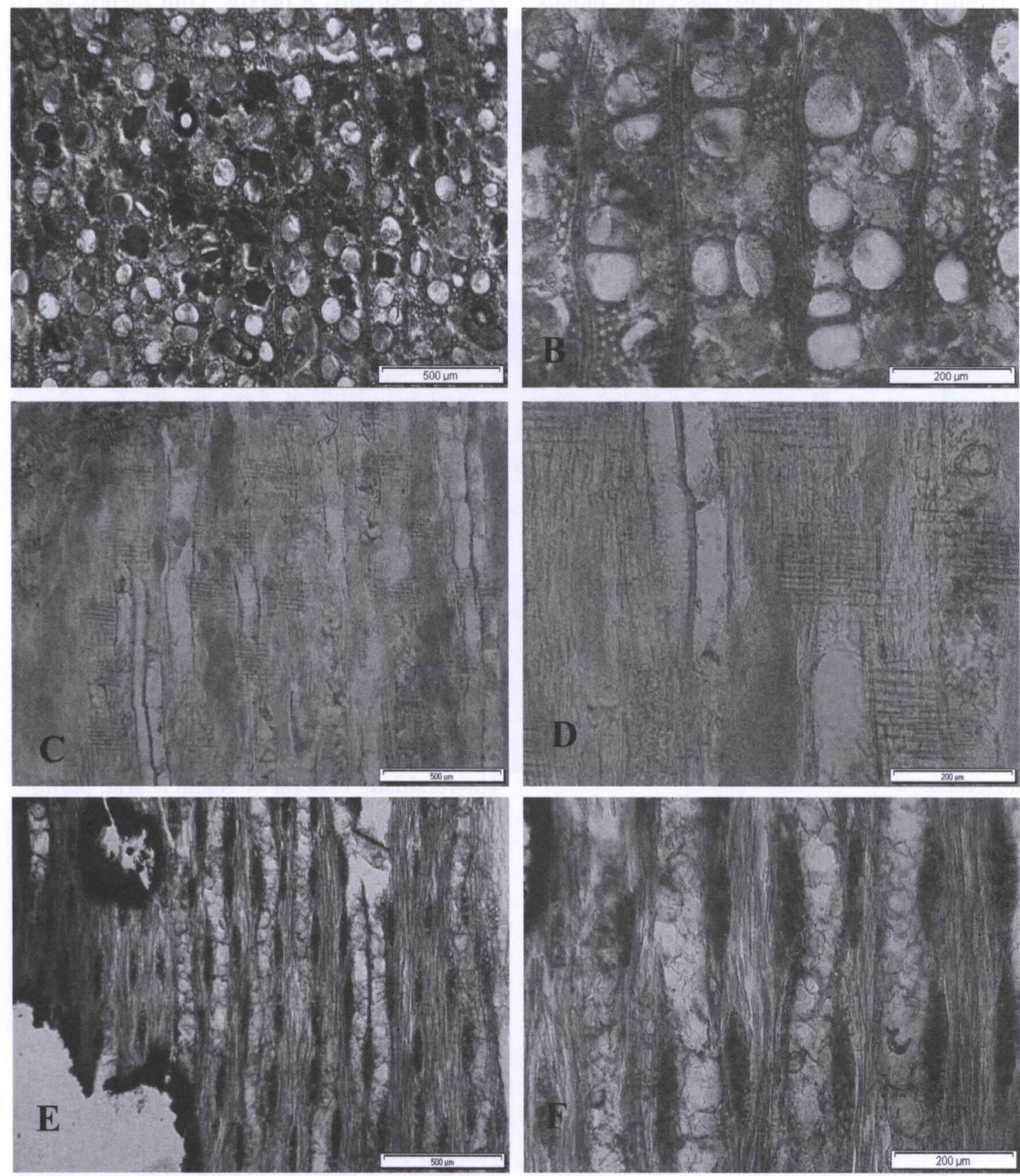

FIGURA 2 - Fotomicrografias do fragmento de madeira. A - Porosidade difusa, poros ovais muito numerosos e parênquima vasicêntrico incompleto, em seção transversal. B - Mesmos aspectos da imagem anterior, com maior aumento. C - Elementos vasculares retilíneos e raios homogêneos, em seção radial. D - Raios compostos inteiramente de células procumbentes e fibras de paredes espessas a muito espessas, em seção radial. E - Madeira de estratificação completa, em seção tangencial. F - Estratificação completa, fibras de paredes espessas a muito espessas e linhas vasculares retilíneas, com abundante conteúdo, em seção tangencial. 
vozes guaranis atribuídas aos ipês (Peralta \& Osuna, 1950; Dimitri, 2000). Na mesma linha, o padre Antônio Sepp informa que "para las cumbreras de las Iglesias o casa del padre" usava-se madeira de "Tuxifo", uma clara corruptela de Taji-hü, segundo a moderna grafia guarani. Por sua vez, Félix de Azara (1847) registrou que o Lapacho era a madeira preferida para tabuados, vigas, tesouras e outros fins construtivos, por sua notável durabilidade natural.

Árvore de grande porte, com troncos retos e diâmetro considerável em indivíduos adultos, 0 ipê-roxo fornece madeira famosa por sua resistência e durabilidade. A escolha do ipê, presentemente comprovada em fragmento da parte carbonizada do esteio no átrio da igreja de São Lourenço Mártir, demonstra que os jesuítas responsáveis pelas construções eram arquitetos experientes e bons observadores, pois souberam escolher uma das melhores madeiras para fins construtivos, existentes na região missioneira do Rio Grande do Sul.

\section{REFERÊNCIAS BIBLIOGRÁFICAS}

AZARA, F. de. Descripcion é Historia del Paraguay y del Río de la Plata. Madrid: Imprenta de Sanchiz, 1847. v. $1.346 \mathrm{p}$.

CARDIEL, J. Las Misiones del Paraguay. Madrid: Historia 16, 1989. 204 p.

DIMITRI, M. J. El nuevo libro del arbol: espécies forestales de la Argentina oriental. Buenos Aires: El Ateneo, 2000. v. 2. 124 p.

PERALTA, A. J., OSUNA, T. Diccionario GuaraniEspañol y Español-Guaraní. Buenos Aires: Editorial Tupã, 1950.427 p.

RECORD, S. J. Woods of storied structure. Tropical Woods, n. 76, p. 32-47, 1943.

RECORD, S. J., HESS, R. W. American timbers of the family Bignoniaceae. Tropical Woods, n. 63, p. 938, 1940.

RECORD, S. J., HESS, R. W. Timbers of the New World. New Haven: Yale University Press, 1943. 640 p. SEPP, P. A. Viagens às Missões Jesuíticas e trabalhos apostólicos. São Paulo: Livraria Martins / Editora da Universidade de São Paulo, 1972. 206 p. 